\title{
On Radiation from Convexo-Concave Microstrip Patch Antenna with Impedance Matching Transformer
}

\author{
Kanika Joshi \\ Research Scholar, Department of Electronics \& Communication, \\ Manipal University Jaipur, India \\ Dr. Dheeraj Bhardwaj \\ Assistant Professor, Department of Physics, \\ BIT-Mesra- Jaipur Campus, Jaipur, India. \\ Dr. Vivekanand Tiwari \\ Professor, Department of Electronics \& Communication, \\ Manipal University Jaipur, India.
}

\begin{abstract}
In this paper the performance of a convexo concave patch antenna is investigated and all results are systematically presented. The angle for the concave arch and convex arch is taken to be 400 . In this modified antenna impedance matching is achieved by impedance matching transformer. The first bandwidth is of $0.0351 \mathrm{GHz}$ at center frequency $3.03 \mathrm{GHz}$ and the second bandwidth is of $0.0257 \mathrm{GHz}$ at center frequency $5.28 \mathrm{GHz}$. The bandwidth, gain, directivity and are marginally improved than a rectangular patch antenna. The radiation patterns of proposed antenna in the entire frequency range are identical in shape and directed normal to patch geometry.
\end{abstract}

Keywords - CONVEXO-CONCAVE, RECTANGULAR MICROSTRIP ANTENNA, IMPEDANCE MATCHING TRANSFORMER

\section{INTRODUCTION}

Microstrip antennas are one of the most widely studied antenna structures perhaps due to their inherent properties like compact size, light weight and their capability to get integrated with other circuit components [2]. However their narrow bandwidth and low gain performance restrict their possible applications in modern communication systems. Broadband antennas are generally preferred in modern wireless communication systems while circularly polarized antennas are preferred in space communication systems. Looking inherent limitations of conventional patch antennas, several alterations in patch geometries were proposed in recent times to achieve circularly polarized broadband antennas [3-4].

One of the methods is to use a concave-convex patch structure as described by Garima and et al whose impedance and axial ratio bandwidths were remarkably improved by using the stacked patches, thin film, thick foam and a probe feed [1]. It is observed that introduction of concavity along the width of the patch antenna improves its impedance value [5].

In this paper we have simulated the radiation performance of a single layer; single feed concave-convex patch antenna designed using a glass epoxy FR-4 substrate. The feed mechanism used here is strip line feed with a matching transformer. Its performance is compared with the radiation performance of a single feed rectangular patch antenna designed on glass epoxy FR-4 substrate.

\section{ANTENNA DESIGN AND RESULTS}

\section{A. Conventional rectangular patch antenna}

In this paper, first a single layered conventional rectangular patch antenna is considered as shown in figure -1 and its radiation performance is simulated by applying ANSYS electronic Desktop [7]. The patch has dimensions ' $\mathrm{L}$ ' $=19.98 \mathrm{~mm},{ }^{\prime} \mathrm{W} '=26.06 \mathrm{~mm}$ and it designed on glass epoxy FR-4 substrate $\left(\varepsilon_{\mathrm{r}}=4.4, \tan \delta=\right.$ 
0.025 , substrate thickness ' $h$ ' $=1.59 \mathrm{~mm})$. Single line feed arrangement at $(9.9 \mathrm{~mm}, 0.634 \mathrm{~mm})$ is applied to excite this antenna. The length of the feed line is $\mathrm{W}_{\mathrm{L}}=7.3 \mathrm{~mm}$ and the thickness of the feed line is $\mathrm{W}_{\mathrm{T}}=1.26875 \mathrm{~mm}$.

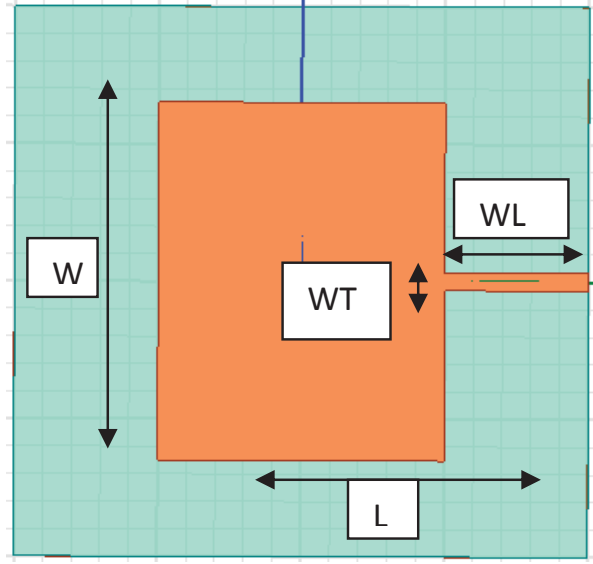

a)

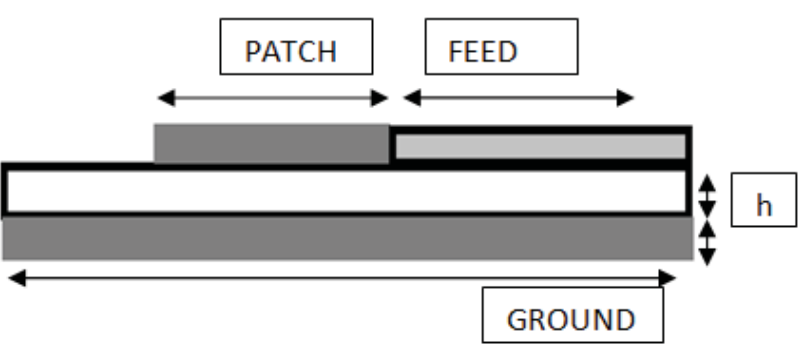

b)

Fig.1. Geometry of conventional rectangular patch antenna a) Top view, b) Side View.

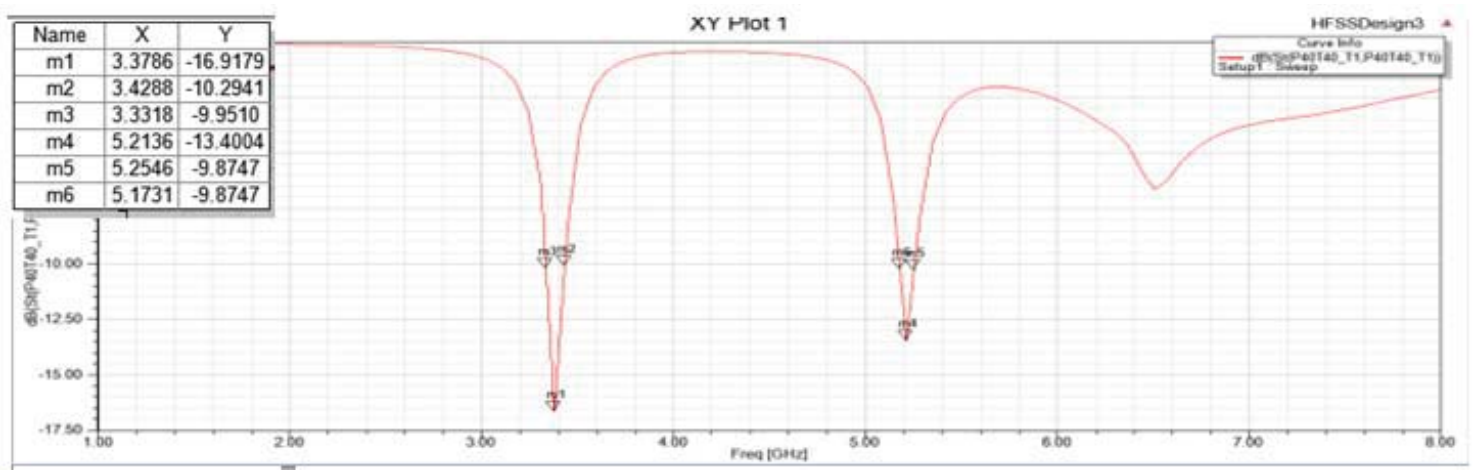

Fig. 2. Variation of S11 parameter as a function of frequency

The simulated $S_{11}$ parameter variation of this antenna as a function of frequency is shown in figure 2 . This indicates that antenna resonates at two different frequencies $3.37 \mathrm{GHz}$ and $5.21 \mathrm{GHz}$ corresponding to its dominant TE10 mode and the impedance bandwidth of this antenna $2.86 \%$ and $1.4 \%$ respectively. The gain of this antenna is $3.49 \mathrm{dBi}$ and $3.96 \mathrm{dBi}$. The band width, gain and efficiency of antenna are very low and hence this antenna in its present form is not suitable for application in modern communication systems.

\section{B. Convexo-concave Microstrip patch antenna}

The rectangular patch antenna is modified by applying a circular arc along its width with radius of curvature $\mathrm{R}_{1}$ while another circular arc parallel to the previous arc with radius of curvature $R_{2}$ is applied in the opposite arm as shown in figure 3. The radius of curvature is optimized to achieve best performance and it is realised that on making $\mathrm{R}_{1}=53.5 \mathrm{~mm}$, best performance with this structure may be achieved [1]. The rectangular patch antenna is modified further by applying another circular arc parallel to the previous arc with radius of curvature $R_{2}$ as shown in figure 3 . The radius of curvature is again optimized to achieve best performance and it is realised that on making $\mathrm{R}_{2}=10 \mathrm{~mm}$, best performance with this structure may be achieved. 


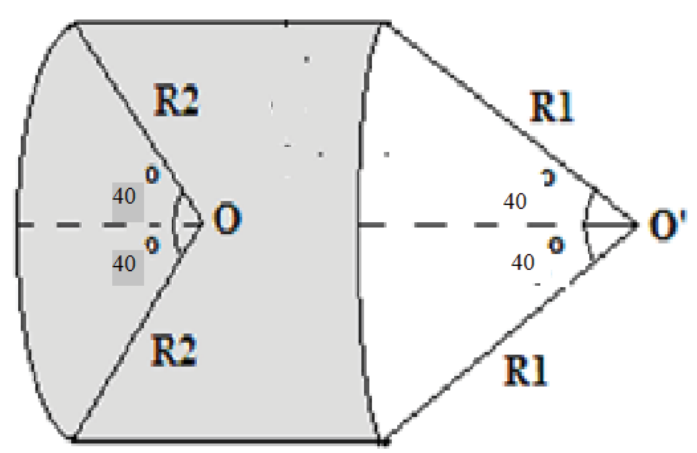

a)

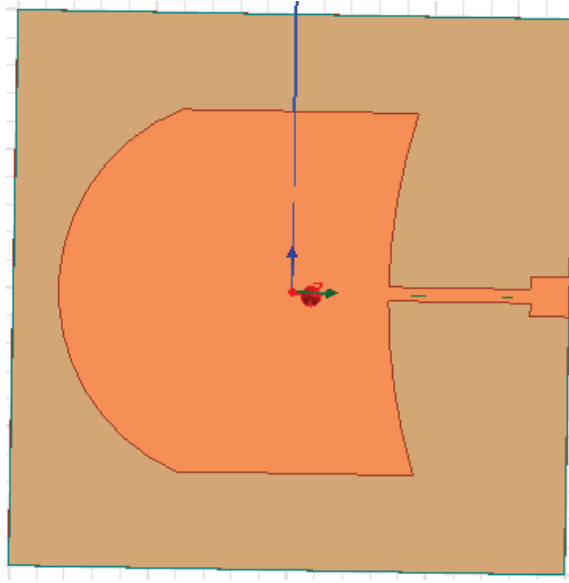

b)

b) Design of convexo-concave patch antenna in HFSS software

Fig. 3. a) Geometry of convexo-concave patch antenna

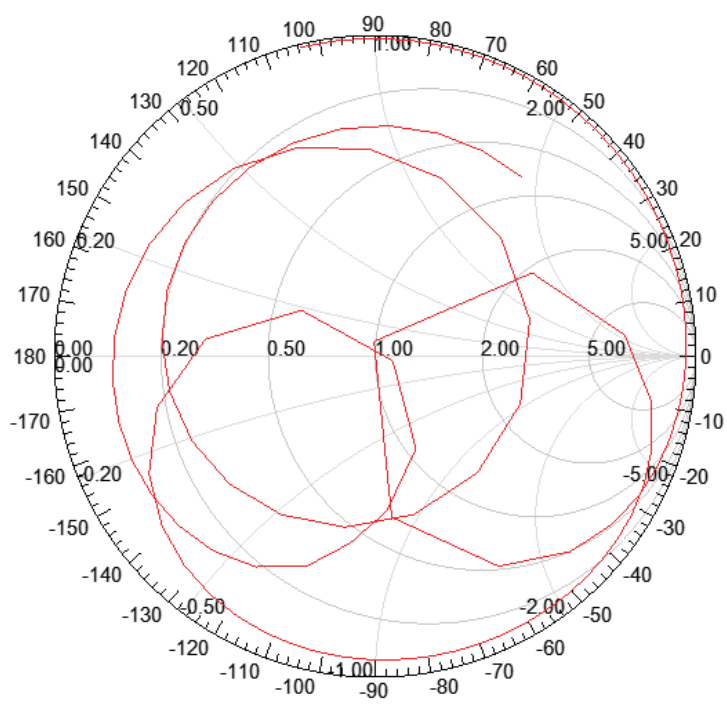

Fig. 4. Smith chart of the convexo-concave patch

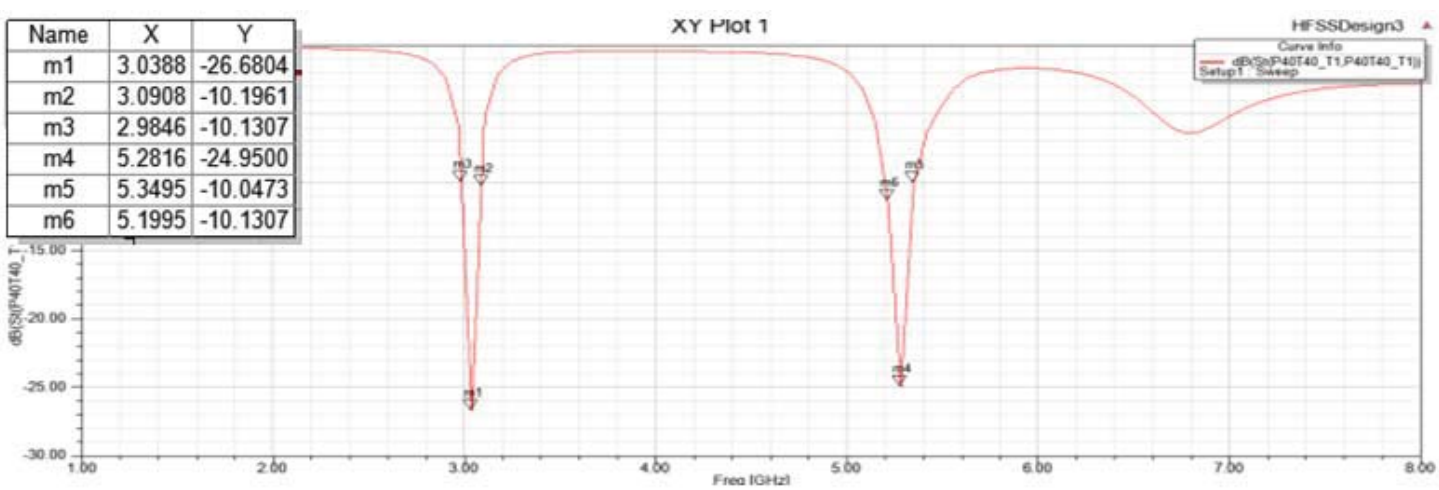

Fig. 5. Variation of $\mathrm{S}_{11}$ parameter as a function of frequency 


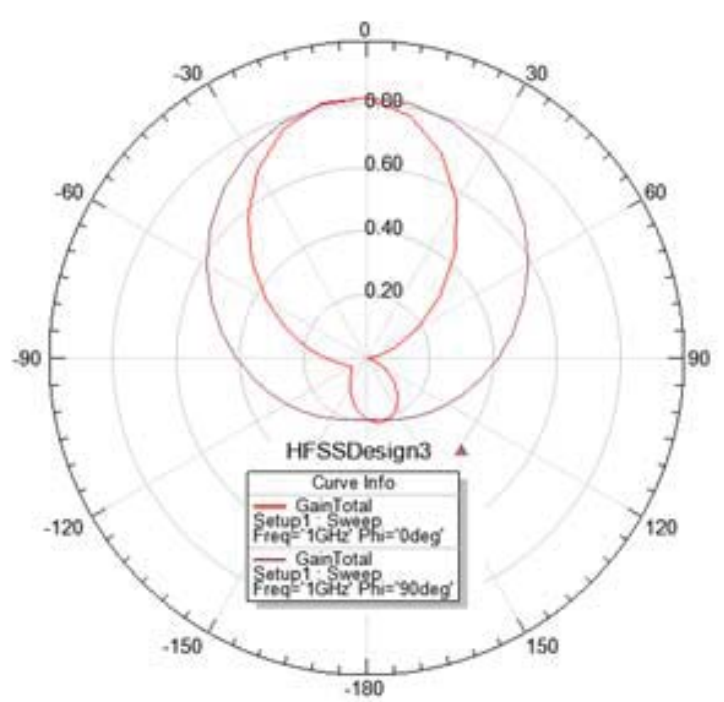

Fig. 6.Radiation pattern for convexo-concave patch antenna

Single line feed arrangement at $(6.9 \mathrm{~mm}, 0.5 \mathrm{~mm})$ is applied to excite this antenna. The length of the matching transformer is $\mathrm{W}_{\mathrm{L}}=10.3 \mathrm{~mm}\left(0.36\right.$ and the thickness of the matching transformer is $\mathrm{W}_{\mathrm{T}}=1 \mathrm{~mm}$. The width of the feed is $F_{w}=1(0.36 \lambda / 2) \mathrm{mm}$ and length of the microstrip feed is $F_{L}=2.9 \mathrm{~mm}$. The simulated smith chart and $\mathrm{S}_{11}$ parameter as a function of frequency of this convexo-concave antenna is shown in figure 4 and figure 5 . Antenna is now resonating at two closely spaced frequencies $3.03 \mathrm{GHz}$ and $5.28 \mathrm{GHz}$. As observed from the $\mathrm{S}_{11}$ plot the value of impedance matching at the two frequencies has decreased. The simulated impedance bandwidth for band 1 is $0.0351 \mathrm{GHz}$ or $3.51 \%$ and for band 2 is $0.0257 \mathrm{GHz}$ or $2.57 \%$ corresponding to central frequency. The gain of modified antenna is $3.7 \mathrm{dBi}$ and $4.7 \mathrm{dBi}$ corresponding to the resonance frequencies 3.03 $\mathrm{GHz}$ and $5.28 \mathrm{GHz}$.

\section{CONCLUSIONS}

In this paper, the performance of a convexo concave patch antenna is investigated and all results are systematically presented. The angle for the concave arch and convex arch is taken to be $40^{\circ}$. The first bandwidth is of $0.0351 \mathrm{GHz}$ at center frequency $3.03 \mathrm{GHz}$ and the second bandwidth is of $0.0257 \mathrm{GHz}$ at center frequency $5.28 \mathrm{GHz}$. The bandwidth, gain, directivity and are marginally improved than a rectangular patch antenna. In this modified antenna impedance matching is achieved by impedance matching transformer.

\section{ACKNOWLEDGEMENTS}

It is with great pleasure that the authors express their sincere thanks and gratitude to Dr. Abhinav Dinesh for providing simulation facilities at BIT Mesra Jaipur Campus and Dr. Deepak Bhatnagar for extending their valuable support along with the microwave laboratory at University of Rajasthan, Jaipur, India.

\section{REFERENCES}

[1] Garima and et al, "Stacked Arrangement of Convexo-Concave Antenna and Simple Rectangular Patch Antenna for Modern Communication Systems", Journal of International Academy of Physical Sciences, Vol. 15 No.4 (2011), pp. 493-501, 2011.

[2] R. Garg, P. Bhartia, I. Bahl, and A. Ittipiboon," Microstrip Antenna Design Handbook", Artech House, Norwood, Mass, USA, 2001.

[3] N. Hercovici, Z. Sipus and D. Bonefacic, "Circularly polarized single-fed wide band microstrip patch", IEEE Trans. Antennas and Propagation, 51 (2003) 1277-1280.

[4] S. Egashira and E. Nishiyama, "Stacked micro strip antennas with wide bandwidth and high gain". IEEE Trans. Antennas and Propagation, 44 (1996) 1533-1534.

[5] Ali Farahbakhsh and et al, "Reduction of mutual coupling in microstrip array antennas using concave rectangular patches", The 2009 International Symposium on Antennas and Propagation (ISAP 2009), October 20-23, 2009, Bangkok, Thailand.

[6] Rajeshkumar V and et al, "Design and Comparative Study of Pin feed and Line feed Microstrip Patch Antenna for X-band Applications", International Journal of Applied Information Systems (IJAIS) - ISSN : 2249-0868 Foundation of Computer Science FCS, New York, USA Volume 1- No.5, February 2012. 
[7] Rajeshkumar V and et al, "Design and Comparative Study of Pin feed and Line feed Microstrip Patch Antenna for X-band Applications", International Journal of Applied Information Systems (IJAIS), ISSN : 2249-0868 Foundation of Computer Science FCS, New York, USA Volume 1- No.5, February 2012.

[8] ANSYS electronics desktop 2015

[9] Dheeraj Bhardwaj, D. Bhatnagar, S. Sancheti and Brijesh Soni "Design of square patch antenna with a notch on FR4 substrate" IET Microwaves, Antenna and Propagation, Vol. 2, No. 8, pp. 880-885, 2008.

[10] Dheeraj Bhardwaj, D. Bhatnagar, S. Sancheti, Brijesh Soni, "Radiations from double notched square patch antenna on FR4 substrate", Journal of Microwaves, Optoelectronics and Electromagnetic Applications, Vol. 7, No.2, December 2008, pp 54-65. 